\title{
Dilution Effects on the Controlled Auto-Ignition (CAI) Combustion of Hydrocarbon and Alcohol Fuels
}

\author{
Aaron Oakley, Hua Zhao, and Nicos Ladommatos \\ Brunel University, UK \\ Tom Ma \\ Ford Motor Company
}

\begin{abstract}
This paper presents results from an experimental programme researching the in-cylinder conditions necessary to obtain homogenous CAl (or $\mathrm{HCCl}$ ) combustion in a 4-stroke engine. The fuels under investigation include three blends of Unleaded Gasoline, a 95 RON Primary Reference Fuel, Methanol, and Ethanol. This work concentrates on establishing the CAI operating range with regard to Air/Fuel ratio and Exhaust Gas Re-circulation and their effect on the ignition timing, combustion rate and variability, Indicated thermal efficiency, and engine-out emissions such as NOx. Detailed maps are presented, defining how each of the measured variables changes over the entire CAI region.
\end{abstract}

Results indicate that the alcohols have significantly higher tolerance to dilution than the hydrocarbon fuels tested. Also, variations in Gasoline blend have little effect on any of the combustion parameters measured.

\section{INTRODUCTION}

Controlled Auto-Ignition (CAI) combustion technology is receiving increased attention for its potential to improve both the efficiency and emissions of IC engines. Although this technology has been available for some time, incorporated into some 2-Stroke engines (e.g. Honda ARC 250), it is a main objective of current research to transfer the technology to 4-Stroke engines to eliminate problems associated with the gas exchange process of 2-Stroke engines that result in higher emissions. Many studies [1-19] have shown that the known strategies for achieving this type of combustion in any engine can lead to severe restrictions on the load and/or speed range attainable, for a variety of reasons. Development of practical systems $[15,18,20]$ appears to be focussed on hybridisation of CAl technology with those already existing ( $\mathrm{SI}, \mathrm{Cl}$, Electric) to provide a complete power plant retaining all of the benefits of CAI combustion (low emissions, high efficiency) without the drawbacks (limited speed and load range). Unfortunately, this approach means that the fuels used in these types of systems must be optimised for both CAI and $\mathrm{SI}$ or $\mathrm{Cl}$ combustion regimes while fulfilling all the normal requirements of reliable cold start, fast warm-up, knock free-operation etc..
The fuelling requirements for $\mathrm{SI}$ and $\mathrm{CAI}$ combustion can be considered as conflicting. On the one hand, SI combustion requires a fuel with a high resistance to autoignition to prevent knocking combustion, and on the other CAl combustion favours a fuel that auto-ignites over a wide range of in-cylinder conditions. The challenge is therefore to optimise a fuel that can best meet both $\mathrm{SI}$ and $\mathrm{CAI}$ requirements in the hybrid engine. In more precise terms, the fuel must be designed to have a specifically varying resistance to auto-ignition dependent on pressure, temperature and chemical histories of the cylinder charge. However, before an optimisation process can be considered, it is first necessary to investigate how the CAl combustion of various candidate fuels is affected by changes in incylinder conditions such as the EGR rate, A/F ratio, compression ratio, and initial charge temperature.

Although this research area has progressed considerably since Onishi et. al. [1] and subsequently Noguchi et. al. [2] demonstrated 2-Stroke CAI (or ATAC), the largest problem still facing researchers is associated with the control of combustion phasing over a wide speed/load range. Over the years, one (or a combination) of four methods has been proposed to affect changes in combustion parameters:

1. Initial charge temperature

2. Compression ratio

3. Fuel blend

4. Recycling of burned gases

The effects of initial charge temperature have been widely reported, ever since Najt and Foster [3] showed that Homogenous Charge Compression Ignition ( $\mathrm{HCCl})$ combustion could be achieved in a SI 4-Stroke engine under lean fuelling and elevated inlet charge temperatures $\left(\sim 300-500^{\circ} \mathrm{C}\right)$. In all cases, the effect of increasing inlet charge temperature is to advance autoignition timing and decrease combustion duration. Aoyama et. al. [6] also showed that the lean-burn limit, defined by hydrocarbon emissions and combustion efficiency, can be extended with increased initial charge temperature. However, this strategy is generally not considered as a practicable method for achieving combustion control due to the high thermal inertia of heating systems. 
Compression ratio effects on ignition timing are also widely understood. Increasing compression ratio has a similar effect as raising the inlet charge temperature; to increase the end-of-compression temperature above that required for spontaneous ignition. Systems that achieve combustion-timing control through changes in compression ratio can be divided into two types: (i) ones that vary the combustion chamber geometry, and (ii) ones that vary the cylinder volume at Inlet Valve Closure (IVC). Type (i) was investigated by Nakano et. al. [16]. They used a combination of a piston mounted in the cylinder head (to vary the combustion chamber geometry) and varying quantities of external EGR as two tools for timing control. Type (ii) requires the use of a Variable Valve Actuation (VVA) system so that control over IVC timing can be independently varied with respect to the other valve timing events. These types of systems are under development and are only just becoming commercially available, explaining why little work has been done to date. The effect of boosting the intake pressure has a similar effect as increased compression ratio - to raise the end-of-compression temperature. However, boosting is more versatile because it allows one to increase the density of the charge without changing its overall composition. Thus, higher engine loads can be achieved with a minimal effect on exhaust NOx emissions, as shown by Aoyama et. al. [6].

The effects of fuel blends have been studied by a number of authors [5,9,10,12,19]. Christensen et. al. [12] achieved homogenous CAl with a number of Primary Reference Fuels (PRFs) and mixtures of Gasoline and Diesel, operating at various compression ratios and intake temperatures. Combustion efficiencies were adversely affected by increasing compression ratio, reducing the expected rise in fuel conversion efficiency. On the whole, the CAl combustion efficiencies of mixtures containing Diesel fuel were seriously affected by poor combustion due to poor fuel vaporisation. Under ambient intake conditions, gasoline fuel (95 RON) was surprisingly more difficult to force into CAl combustion (through increased compression ratio) than Isooctane (100 RON). Olsson and Johansson [20] demonstrated how the composition of a PRF (Isooctane/Heptane) fuel can affect ignition timing so that combustion can be controlled over a wide load range with additional inlet boost pressure. All of these types of systems add complexity to engine control and require additional ancillaries, which may make them unsuitable for certain types of vehicles.

Control over the recycling of burned gases can include variations of both the prompt residual rate and external EGR rate to achieve proper combustion phasing. The effect of changes in the residual gas rate was investigated by Lavy et. al. [15], who presented preliminary results from the collaborative 4SPACE (4Stroke Powered gasoline Auto-ignition Controlled combustion Engine) project, investigating all aspects of CAI combustion. 3D CFD analyses on a suitable 2-stroke engine were undertaken to determine the global and local in-cylinder conditions necessary for CAI combustion. They found that the occurrence of CAl is dominated by the degree of mixing between fresh charge and exhaust gas residuals. 4-stroke concepts were developed to mimic the internal fluid dynamic and mixing effects of the 2-stroke when running in CAl mode, resulting in the first 4-stroke engine able to achieve CAI over a limited load and speed range without the use of external charge heating or high compression ratio. This was achieved using altered valve timing, lift, and duration. Law et. al. [18] presented two methods of controlling the EGR rate. The first was similar to Lavy et. al. [15], and the second involved the storage of exhaust gas in the exhaust manifold prior to readmission to the combustion chamber during the intake stroke. They have shown that both methods are effective in controlling combustion timing and duration.

The method of varying residual gas rate has been shown to work using both mechanical [15] and electro-hydraulic [18] valve actuation. Residual gas systems are attractive because of three fundamental properties:

1. High temperature residuals aid auto-ignition (of gasoline)

2. Switching from SI to CAI may be done in a single cycle.

3. Degree of residual mixing with fresh charge may be used to control combustion timing and duration

The third property is what distinguishes stratified CAI combustion from $\mathrm{HCCl}$. It is the mixing process between the fresh charge and residuals that establishes the temperature and residual stratification, and ultimately determines the combustion phasing.

Although the use of burned gas residuals has so far proven to be the most practicable for achieving CAI, there has been a limited amount of detailed work investigating the effects of exhaust gas dilution on CAI or $\mathrm{HCCl}$ combustion $[3,4,8,11,16]$. Thring [4] investigate the effects of $A / F$ ratio, EGR rate, fuel type, and compression ratio on the attainable homogenous CAI combustion region and engine-out emissions. He found that 4-stroke CAI maximum loads could not approach those of 2-stroke CAl engines under the conditions chosen. He also identified that detailed analyses of the heat-release characteristics over the CAI range would be useful for further understanding. For the most part, papers that investigate EGR dilution effects do so by either fixing the $A / F$ ratio or the fuelling rate. The authors believe that the effect of air and EGR dilution should be investigated simultaneously so that the relative contributions of each type can be quantified in terms of effects on combustion parameters.

The work presented in this paper forms part of the 4SPACE project and follows on from results already presented by the authors $[17,19]$. It is a parametric survey designed to investigate how CAl is affected by a number of engine operating conditions, including Air/Fuel ratio, in-cylinder EGR fraction, compression ratio, initial charge temperature, and fuel effects such as octane and blend. The specific fuels under investigation are 3 blends of Gasoline, Methanol, Ethanol and a PRF (95 RON). With respect to the $A / F$ ratio and $E G R$ rate, the range of 
successful CAI operation is comprehensively defined for fixed inlet charge temperature and compression ratio. Heat release analysis is performed to evaluate combustion characteristics throughout the range of operation for each fuel. In this way, the air and exhaust gas dilution effects on CAI combustion can be evaluated independently of any other operating variables, while allowing further cross-comparisons to be made between fuel types. The experimental approach is similar to that of Thring [4]. However, this work goes further by presenting full maps of each of the measured variables, including detailed heat release analyses data. Furthermore, the authors believe that this work will prove extremely useful for those developing CAI combustion models of real-world fuels.

\section{EXPERIMENTAL PROCEDURE}

Our previous papers $[17,19]$ cover the engine setup and experimental procedures in some detail, so this section shall only briefly describe the conditions under which we performed all tests. Figure 1 details how external EGR was passed from the exhaust to intake manifolds. Gas analysers measured intake and exhaust species concentrations, from which in-cylinder EGR fraction and $\mathrm{A} / \mathrm{F}$ ratio are calculated.

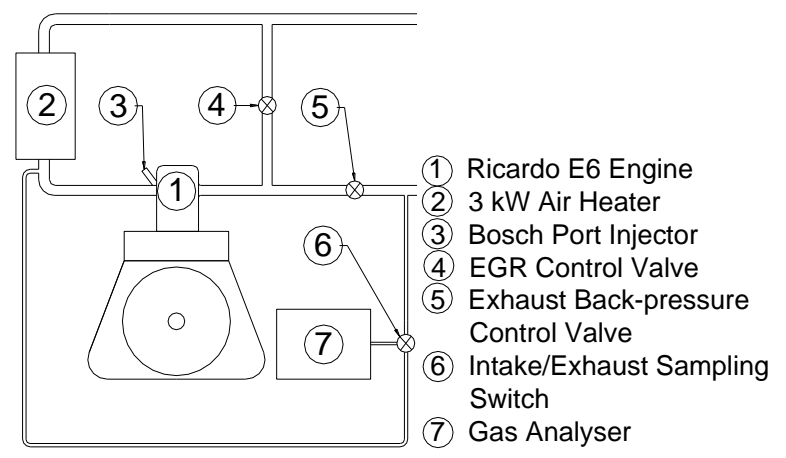

Figure 1 External EGR and gas sampling systems

As with any experimental tests, we have a number of fixed parameters, independent variables, and dependent variables. The fixed parameters are:

$\begin{array}{ll}\text { Engine Speed: } & 1500 \mathrm{rpm} \\ \text { Airflow: } & \text { WOT } \\ \text { Inlet charge temperature: } & 320 \pm 1{ }^{\circ} \mathrm{C} \\ \text { Coolant temperature } & 80 \pm 0.2^{\circ} \mathrm{C} \\ \text { Oil temperature } & 55 \pm 1^{\circ} \mathrm{C} \\ \text { Compression ratio } & 11.5\end{array}$

Exhaust Backpressure Injection Timing

0.15 bar gauge

$79^{\circ} \mathrm{CA}$ BTDC

Compression Stroke

The fuelling and external EGR rates are varied to obtain different combinations of in-cylinder exhaust gas and air dilution (independent variables) rates respectively. The result is a number of 3-dimensional maps that detail how the dependent variables (combustion timing, duration, IMEP, Indicated Thermal Efficiency) change over the dilution ranges.

In previous studies, some authors have chosen to keep the ignition timing as one of the fixed conditions during testing. This was done so that combustion phasing was kept optimal, and trends of combustion duration and emissions would be predictive of a practical engine operating in this mode. However, for those predictions to be correct, the practical CAI engine must use either the compression ratio or inlet charge temperature parameters to control the combustion phasing, neither of which has yet proven to be practicable. In the present work, the authors could have chosen to perform the experiments in the same way as described above. In that case, Inlet temperature or compression ratio would be varied resulting in changes in the pressure and temperature histories over the dilution ranges. This presents a problem when trying to compare different fuel types: comparison of two fuels operating under similar exhaust gas and air dilution conditions is unreliable if the charge temperature and pressure histories are vastly different, unless it is these parameters that one wishes to study. So, to investigate the charge dilution effects independently of any other effects (pressure/temperature histories), the intake charge temperature and compression ratio have been fixed for all dilution rates and for all fuels. That said, there are secondary effects associated with fuel and EGR properties that conspire to change the charge temperature and pressure histories over the dilution ranges. However, in our opinion these cannot be avoided and may be considered as dilution effect in their own right.

FUELS - The fuels used fall into three categories. The alcohols included are Methanol and Ethanol, since they are already in use for automotive applications, and previous studies $[5,7,22,23]$ have shown alcohols to be superior to Gasoline for CAl operation. A PRF blend of 95\% Isooctane and 5\% Heptane (95 RON) is included for comparison with Gasoline. Both the alcohols and the PRF fuels are HPLC grade, with a purity greater than $99.9 \%$. 


\begin{tabular}{|c|c|c|c|c|}
\hline & $\begin{array}{c}\text { Type } 1 \\
\text { Distilled from Type } 2\left(\text { IBP }^{\star}-90^{\circ} \mathrm{C}\right)\end{array}$ & \multicolumn{2}{|c|}{$\begin{array}{c}\text { Type } 2 \\
\text { BP Premium Unleaded Gasoline }\end{array}$} & \begin{tabular}{|c|} 
Type 3 \\
Distilled from Type $2\left(90^{\circ} \mathrm{C}-\mathrm{FBP}^{*}\right)$
\end{tabular} \\
\hline & & \multicolumn{2}{|c|}{ BS EN 228 Marketing Specification } & \\
\hline & & MIN & MAX & \\
\hline Aromatics & 15.5 & \multicolumn{2}{|c|}{34.1} & 47.5 \\
\hline Paraffins & 72.1 & \multicolumn{2}{|c|}{58.3} & 42.6 \\
\hline Olefins & 12.4 & \multicolumn{2}{|c|}{7.6} & 9.9 \\
\hline Research Octane Number (RON) & 93.5 & 95 & & 98 \\
\hline Motor Octane Number (MON) & 85 & 85 & & 86.5 \\
\hline Fuel Sensitivity (RON-MON) & 8.5 & \multicolumn{2}{|c|}{10} & 11.5 \\
\hline Total lead $(\mathrm{g} / \mathrm{l})$ & & & 0.013 & \\
\hline Total Sulphur (\%m/m) & 0.01 & & 0.05 & 0.04 \\
\hline Density $15^{\circ} \mathrm{C}\left(\mathrm{kg} / \mathrm{m}^{3}\right)$ & & 725 & 780 & \\
\hline Vapour Pressure (kPa) & & 45 & 80 & \\
\hline
\end{tabular}

Table 1 Specification and Properties of Gasolines Tested

Table 1 shows the composition and properties of the three full boiling range Gasolines used. Gasolines types 1 and 3 are obtained by distillation of Gasoline type 2 . Full details of how this is undertaken can be

obtained from Oakley et. al. [21]. The three Gasolines are included to study the effects of changing the relative concentrations of aromatics and paraffins on CAI combustion properties. In all cases the fuels are injected just upstream of the intake port onto a closed valve, using a Bosch port fuel injector operating at a pressure of 2.7 bar gauge.

\section{RESULTS AND DISCUSSION}

Investigation of the satisfactory operating region of gasoline was carried out for a range of $A / F$ ratios and EGR rates. In practical terms, this meant recording a set of data points in a region between the richest and leanest lambda values attainable, limited by measured engine knock and partial combustion respectively. The EGR rate was increased in steps for each fuel rate until engine misfire was observed to occur.

IGNITION TIMING diagrams are presented for Gasoline (Type 2), the PRF (95 RON), Methanol, and Ethanol in figure 2. For each of the fuels, the CAI region attainable is bounded on three sides, where combustion exceeds acceptable limits. These boundaries can be defined as:

1. Knock Region. When the fuelling rate is increased (lower lambda), combustion rates also increase, eventually leading to unacceptable in-cylinder pressure rise, which can cause physical damage to the engine.

2. Partial Burn Region. When the fuelling rate is reduced sufficiently (high lambda), the combustion temperature becomes too low to fully oxidize a significant proportion of the fuel. Exhaust $\mathrm{CO}$ and unburned $\mathrm{HC}$ emissions rise rapidly in this region.

3. Misfire Region. At high EGR rates, ignition fails to occur in a small proportion of the cycles due to high concentrations of inert combustion products in the charge.

A full explanation of how these regions are defined can be found in our previous paper [19]. From figure 2 one observes that the CAI region attainable is smallest for the PRF, followed by Gasoline (Type 2), then Ethanol,

and finally Methanol. The PRF not only exhibits the smallest region, but is the only one of these fuels where the region does not extend to stoichiometric conditions. An explanation arises if one considers the trends of ignition timing. The most advanced timing occurs on the knocking boundary, under $0 \%$ EGR conditions. However, this timing is already retarded beyond TDC $\left(\sim 2^{\circ} \mathrm{CA}\right.$ ATDC). It only takes a relatively small concentration of EGR $(>33 \%)$ to retard the ignition beyond acceptable limits, taking combustion into the misfire region. This leads to the curious condition under which the engine is periodically knocking and misfiring when operating at the lowest point on the map (EGR $32 \%$, lambda 1.5). Any increase in fuel or EGR rate causes complete misfire, and any decrease in EGR causes heavy knocking combustion. So, in order to ensure that a stoichiometric mixture can be burned in this mode, copious amounts of EGR combined with a high enough intake charge temperature and/or compression ratio are required. While this appears true for hydrocarbon fuels, it is not the whole story. Figure 2c shows the timing map for Methanol. The map indicates that the Methanol ignition timing is not sensitive to EGR rate. This could be a result of favourable inlet charge temperature / compression ratio conditions, but equally it could arise from Methanol's different oxidation kinetics. In any case, this trend can explain why previous studies $[5,7,22,23]$ have shown Methanol to outperform Gasoline in systems that rely on exhaust residuals to promote auto-ignition. In other words, the combinations of exhaust gas dilution and charge temperature that facilitate auto-ignition are relatively fewer for Gasoline, compared to Methanol, giving Methanol a wider operating range. Moreover, this result can explain why Methanol performs better without including any part that radicals may play in promoting auto-ignition. While the EGR does contain partially oxidized products, any radicals present would be consumed in the intake manifold, if not sooner. The trends for Ethanol ignition timing (Figure 2d) lie between 
trends observed for Gasoline and Methanol, showing some retardation with increased EGR rate. For all of the fuels tested, ignition timings are relatively independent of $\mathrm{A} / \mathrm{F}$ ratio at low EGR rates. However, as EGR rate is increased, ignition timings advance under leaner conditions. At higher EGR rates, the probability of direct contact between the fuel and oxygen molecules is reduced by the increased presence of inert species. For this reason, the oxidation process becomes sensitive to the $\mathrm{A} / \mathrm{F}$ ratio.

COMBUSTION DURATION trends are shown in Figure 3. Unlike ignition trends, combustion duration trends are similar for all of the fuels tested. At low EGR rates, combustion duration is mainly dependent on the $A / F$ ratio: air dilution reduces the heat release rate, increasing the combustion duration. As the EGR rate is increased, duration progressively becomes more dependent on EGR rate. In the region of stoichiometry, the rate of increase in combustion duration with EGR rate is much higher for the hydrocarbon fuels. Again, this indicates that alcohols have a higher tolerance to EGR. Trends would indicate that the onset of knocking combustion is more dependent on combustion duration than on ignition timing. Figure 4 presents the maximum rate of in-cylinder pressure rise trends for each of the fuels. This quantity is related directly to the heat release rate. The most striking comparison is that knocking combustion occurs when the maximum rate of pressure rise exceeds approximately $5 \mathrm{bar} /{ }^{\circ} \mathrm{CA}$ regardless of charge composition. This result tends to reinforce the view that the occurrence of knock is dependent on the heat release rate and not ignition timing, notwithstanding the weak relationship between the combustion phasing and heat release rate.

INDICATED THERMAL EFFICIENCIES are shown in Figure 5. These efficiencies do not include considerations of the energy provided in raising the inlet charge temperature. Generally speaking, highest thermal efficiency occurs at the highest load point, where combustion efficiencies are maximum. The hydrocarbon fuels show maximum efficiencies of around $41 \%$, while the alcohols are slightly higher at $43 \%$. Exhaust unburned $\mathrm{HC}$ and $\mathrm{CO}$ emissions are comparable for each of the fuels at the point of highest efficiency, indicating that combustion efficiencies are also similar. Combustion phasing (at the point of highest thermal efficiency) is best for the alcohols due to their EGR tolerance, which may account for some of the differences. Starting at the highest load point, as mixtures are further diluted with a combination of air or EGR, thermal efficiency drops. Lowest thermal efficiencies are observed as combustion enters the partial burn region with no EGR dilution.

COEFFICIENT OF VARIATION in the Indicated Mean Effective Pressure (COVimep) trends are presented in Figure 6. The first thing to note is that for all fuels, the COVimep exceeds acceptable limits over most of the region. For a practical engine, torque variations should not exceed about $5 \%$ if drivability is not to be affected. Once again, the alcohol fuels exhibit superior combustion, especially towards higher loads. For all fuels, increases in both air and EGR dilution have similar effects, causing higher cyclic variations. As explained earlier, 40\% EGR has a much more pronounced effect on the PRF fuel than on Methanol, leading to its much smaller region.

INDICATED SPECIFIC NOx emissions are presented in Figure 7. Absolute values are extremely low compared to normal $\mathrm{SI}$ or $\mathrm{Cl}$ emissions. Trends appear to be similar between different fuels over the CAI ranges; (relatively) high NOx is observed both at the highest and lowest lambda conditions. High NOx at high lambda is thought to be caused by reduced combustion efficiencies in this region (see Figure 5), since volumetric concentrations of NOx species vary little as the charge is leaned. High NOx is also observed along the edge of the knocking region, as one would expect. However, the PRF shows the highest emissions in this area, followed by Gasoline, then Ethanol, and finally Methanol. The explanation for this lies in where the edge of the knocking region is situated for each fuel: For similar air dilution conditions and $0 \% \mathrm{EGR}$, Methanol has the fastest heat release rate of all the fuels. We have already shown the onset of knock to be related to the heat release rate (Figure 4). Thus, at the onset of knock the Methanol charge, requiring more air dilution than the other fuels, produces lower IMEP than Ethanol, followed by Gasoline, and then the PRF. NOx formation is known to be load dependant, so NOx emissions for Methanol on the knocking boundary are lower.

FUEL BLEND EFFECTS are presented in Figure 8 (a, b, and $c$ ). These charts show how the ignition timing varies over the CAl region for each blend of Gasoline. The similarity is immediately obvious in both trends and absolute values of ignition timing regardless of blend. This would tend to suggest that, unlike SI combustion, CAl combustion is insensitive to fuel blend. This has two consequences:

1. Octane number, which usually defines the quality of a fuel and its suitability for a particular engine is inadequate for fuels with CAI combustion applications.

2. Increasing the paraffinic or aromatic content of Gasoline (changing octane) will have little or no effect on the speed/load range attainable in CAI combustion mode.

Having completed the tests on each Gasoline blend, we set out to understand why blend has no effect on CAI combustion parameters. Consideration of the engine operating conditions may provide some clue. There are a number of differences between Research and Motoring Octane Number tests. However, the primary difference is that of intake charge temperature. The RON test has an intake charge temperature close to ambient $\left(\sim 25^{\circ} \mathrm{C}\right)$, while the motoring octane test has a much higher intake temperature of around $150^{\circ} \mathrm{C}$. Table 1 shows that despite gasoline types 1 and 3 having very different 
RONs of 93.5 and 98 respectively, they have much similar MONs of 85 and 86.5. So, each blend behaves in a similar fashion when SI combustion and high temperature intake charges are used. This effect is associated with fuel sensitivities, and was well documented by Leppard [24]. The known behaviour of fuels under RON and MON conditions would suggest that the three fuel blends would behave similarly under high intake temperature CAI conditions, but as the intake temperature is lowered and the compression ratio increased (to compensate), their behaviours should diverge and relative differences between the fuels should become more apparent.

To test this hypothesis, we decided to operate the engine at its maximum compression ratio of 17.8 , and a minimum intake charge temperature to ensure stable CAI combustion. Unfortunately, this condition requires a minimum intake charge temperature of $135^{\circ} \mathrm{C}$, which is still more like MON test conditions than those of the RON test. During the course of this work, we have found results obtained along the knock line to be good indicators for how the fuel behaves over the entire region. Figure $8 \mathrm{~d}$ shows the position of the knock line for the original and the higher compression ratio/lower intake charge temperature tests. As we have seen, trends from the original tests show very little difference in the position of the knock boundary (Figure $8 \mathrm{a}, \mathrm{b}$ and $\mathrm{c}$ ). Despite our predictions, the knock boundary at the higher compression ratio conditions does not change significantly between blends, reinforcing points 1 and 2 above. Furthermore, the ignition timings that are observed on the knock boundary and 0\% EGR for each fuel are all within $0.5^{\circ} \mathrm{CA}$. So, the conditions we have chosen do not force the blends to behave differently from one another. However, this is not entirely unexpected given the intake temperature conditions required to achieve stable combustion at the engine's maximum compression ratio. Interestingly, each of the knock boundaries for the higher compression tests is truncated in a similar fashion to the PRF fuel results in the original tests. Again, this is because the ignition timing under $0 \%$ EGR conditions is already retarded past TDC $\left(\sim 2^{\circ} \mathrm{CA}\right.$ ATDC), and when EGR is introduced the maximum ignition retard (causing misfire) is reached sooner.

\section{CONCLUSIONS}

CAI combustion at elevated intake charge temperatures has been achieved using a number of fuels including 3 blends of Gasoline, Methanol, Ethanol, and a PRF of 95 RON. In order to study fuel and dilution effects only, a lean-to-stoichiometric operating region has been defined with regard to $A / F$ ratio and $E G R$ rate. Measurements of various combustion parameters have led to the following conclusions:

1. For all fuels tested, the Knock, Misfire, and PartialBurn boundaries always limit the region of acceptable CAI operation.
2. Hydrocarbon fuels showed a much lower tolerance to air and EGR dilution than the alcohols. The most notable example is that Methanol ignition timing is relatively insensitive to EGR rate. Consequently, there was no misfire region for Methanol at high EGR rates. Instead, partial burning was observed (high exhaust $\mathrm{CO}$ and $\mathrm{HC}$ ). These results explain why Methanol is a superior CAl fuel to Gasoline without including any part that radicals may play in the promotion of auto-ignition.

3. The engine was unable to operate under stoichiometric conditions using the PRF. The inlet charge temperature and compression ratio combination chosen was responsible for this, leading to over-retarded ignition timing over the entire CAI region.

4. At low EGR rates, Ignition timing was insensitive to the $A / F$ ratio for all fuels tested. However, reducing $A / F$ ratio increases the heat release rate, which eventually leads to knocking combustion. The onset of knock occurs when the rate of pressure rise exceeds $5 \mathrm{bar} /{ }^{\circ} \mathrm{CA}$ for this engine, and under these operating conditions, regardless of fuel type.

5. Combustion of alcohols leads to higher engine thermal efficiencies when compared to the hydrocarbons. Better combustion phasing may be responsible for this.

6. NOx emissions were generally much lower when compared to $\mathrm{SI}$ or $\mathrm{Cl}$ combustion. However, Methanol exhibited lowest emissions over its CAl region. This is because Methanol has the highest heat-release rate of all the fuels, under these conditions. Therefore, knock-limited combustion is reached at a lower load (lower combustion temperature), resulting in lower NOx.

7. Despite having vastly different composition and knock-resistance, the three blends of Gasoline performed almost identically under two sets of inlet charge temperature/compression ratio conditions.

The results presented here clearly show that large differences in CAI combustion and tolerance to dilution exist between different fuel types, due to differences in oxidation kinetics. Although the commercial use of alcohol fuels are currently limited to certain markets (e.g. South America) for reasons of climate and cost, their application for CAl combustion engines is obvious. Further work is required to determine if alcohol/gasoline blends can exhibit similar CAI combustion advantages. If so, such a fuel may be viable for the global market.

\section{ACKNOWLEDGMENTS}

The authors would like to acknowledge the financial support to the work reported here by EPSRC and the Ford Motor Company. The authors would also like to thank the partners of the Brite-EuRam 4-SPACE project 
for their support and advice throughout the course of this work.

\section{REFERENCES}

1. Onishi, S., Hong Jo, S., Shoda, K., Do Jo, P., and Kato, S., "Active Thermo-Atmosphere Combustion (ATAC) - A New Combustion Process for Internal Combustion Engines", SAE Paper 790501, 1979.

2. Noguchi, M., Tanaka, Y., Tanaka, T., and Takeuchi, Y., "A Study on Gasoline Engine Combustion by Observation of Intermediate Reactive Products during Combustion", SAE Paper 790840, 1979.

3. Najt, P. M., and Foster, D. E., "Compression-Ignited Homogenous Charge Combustion", SAE Paper 830264, 1983.

4. Thring, R. H., "Homogenous Charge Compression-Ignition (HCCl) Engines", SAE Paper 892068, 1989.

5. Lida, N., "Combustion Analysis of Methanol-Fuelled Active Thermo-Atmosphere Combustion (ATAC) Engine Using Spectroscopic Observation", SAE Paper 940684, 1994.

6. Aoyama, T., Hattori, Y., Mizuta, J., Sato, Y., "An Experimental Study on Premixed-Charge Compression Ignition Gasoline Engine", SAE Paper 960081, 1996.

7. Pucher, G. R., Gardiner, D. P., Bardon, M. F., and Battista, V., "Alternative Combustion Systems for Piston Engines Involving Homogenous Charge Compression Ignition Concepts - A review of Studies Using Methanol, Gasoline and Diesel Fuel.", SAE Paper 962063, 1996.

8. Ryan III, T. W., Callahan, T. J., "Homogenous Charge Compression Ignition of Diesel Fuel", SAE Paper 961160, 1996.

9. Amneus, P., Nilsson, D., Mauss, F., Christensen, M., "Homogenous Charge Compression Ignition Engine: experiments and detailed kinetic calculations", $4^{\text {th }}$ International Symposium Comodia 1998, pp. 567-572., 1998.

10. Furutani, M., Ohta, Y., Kono, M., Hasegawa, M., "An ultralean premixed compression-ignition engine concept and its characteristics", $4^{\text {th }}$ International Symposium Comodia 1998, pp. 173-177., 1998.

11. Christensen, M., Johansson, B., "Influence of Mixture Quality on Homogenous Charge Compression Ignition", SAE Paper 982454, 1998.

12. Christensen, M., Hultqvist, A., and Johansson, B., "Demonstrating the Multi Fuel Capability of a Homogenous Charge Compression Ignition Engine with Variable Compression Ratio", SAE Paper 1999-01-3679, 1999
13. Stanglmaier, R. H., and Roberts, C. E., "Homogenous Charge Compression Ignition ( $\mathrm{HCCl})$ : Benefits, Compromises, and Future Engine Applications", SAE Paper 1999-01-3682, 1999.

14. Flowers, D., Aceves, S., Smith, R., Torres, J., Girard, J., and Dibble, R., "HCCl in a CFR Engine: Experiments and Detailed Kinetic Modelling", SAE Paper 2000-01-0328, 2000

15. Lavy, J., Dabadie, J., Angelberger, C., Duret, P. (IFP), Willand, J., Juretzka, A., Schaflein, J. (Daimler-Chrysler), Ma, T. (Ford), Lendresse, Y., Satre, A.(PSA Peugeot Citroen), Schulz, C., Kramer, H. (PCl - Heidelberg University), Zhao, H., Damiano (Brunel University), "Innovative Ultra-low NOx Controlled Auto-Ignition Combustion Process for Gasoline Engines : the 4-SPACE Project", SAE Paper 2000-01-1837, 2000.

16. Nakano, M., Mandokoro, Y., Kubo, S., Yamazaki, S., "Effects of exhaust gas recirculation in homogenous charge compression ignition engines", Int $\mathrm{J}$ Engine Research, Vol. 1 No. 3, pp. 269-279, IMechE 2000

17. Oakley, A., Zhao, H., Ladommatos, N., Ma, T., "Experimental Studies on Controlled Auto-Ignition (CAI) Combustion in a 4-Stroke Gasoline Engine" Int. Conf. $21^{\text {st }}$ Century Emissions Technology, IMechE 2000.

18. Law, D., Kemp, D., Allen, J., "HCCI Mode of Combustion in a Single Cylinder 4-Stroke Engine Fitted With Active Valve Train", SAE Paper 2001-01-0251, 2001.

19. Oakley A., Zhao, H., Ladommatos, N., Ma, T., "Experimental Studies on Controlled Auto-Ignition (CAI) Combustion of Gasoline in a 4-Stroke Engine", SAE Paper 2001-01-1030, 2001.

20. Olsson, J., Johansson, B., "Closed Loop Control of an HCCI Engine", SAE Paper 2001-01-1031, 2001.

21. Oakley, A., Zhao, H., Ladommatos, N., Ma, T., "Feasibility Study of an Online Gasoline Fractionating System For Use in Spark-Ignition Engines", SAE Paper 2001-01-1193, 2001.

22. Duret, P., Lavy, J., "Gasoline Controlled Auto-Ignition $\left(C A I^{T M}\right)$ : potential and prospects for future automotive application", Int. Conf. $21^{\text {st }}$ Century Emissions Technology, IMechE 2000.

23. Norimasa, I., Ichikura, T., Kase, K., Yoshiteru, E., "SelfIgnition and combustion stability in a methanol fuelled low heat rejection ceramic ATAC engine - analysis of cyclic variation and high wall temperatures and lean burn operation", JSAE Paper 0389-4304/97, 1997.

24. Leppard, W. R., "The Chemical Origin of Fuel Octane Sensitivity", SAE Paper 902137, 1990. 

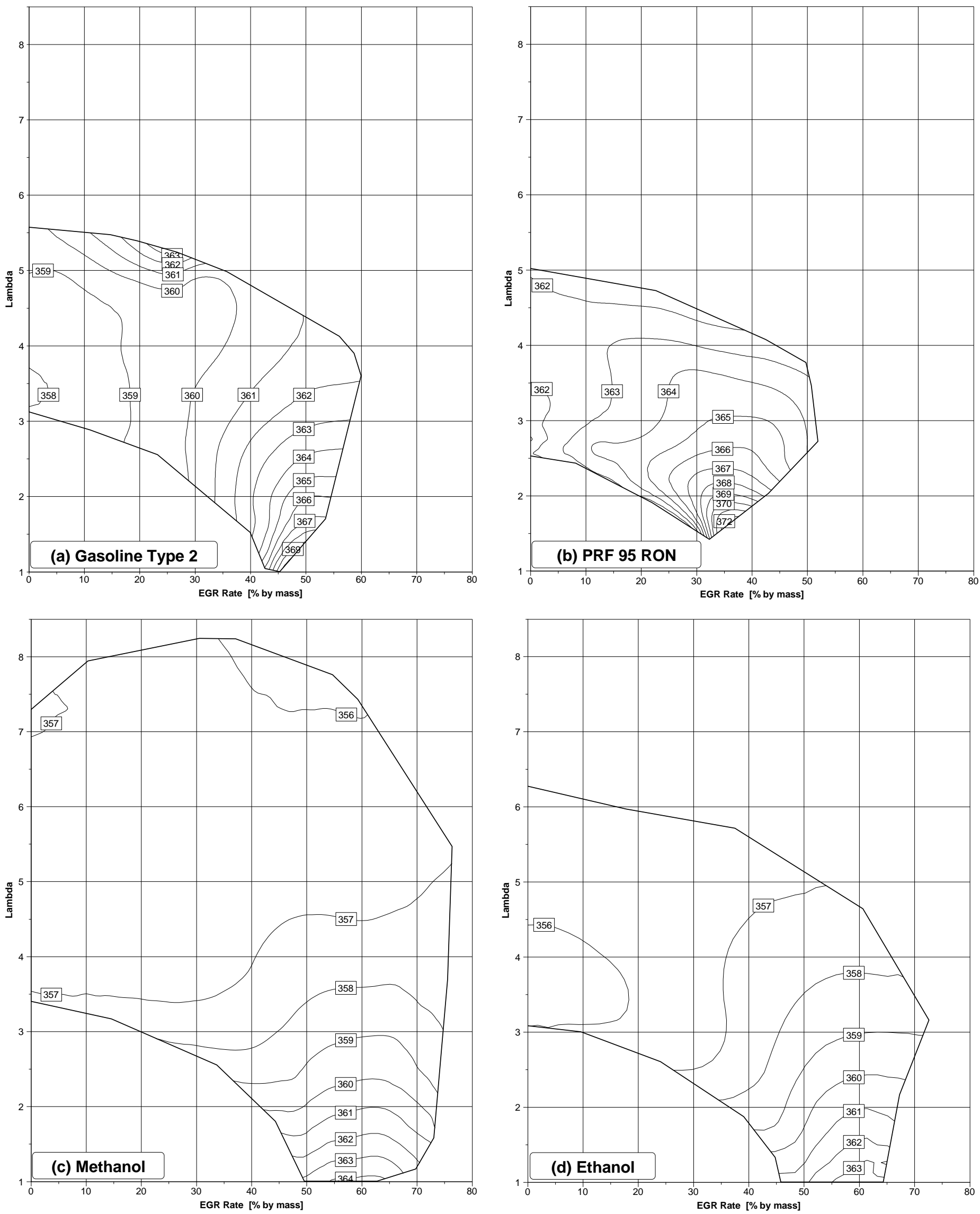

Figure 2 Ignition Timing (10\% Burn Crank Angle), $\left({ }^{\circ} \mathrm{CA}, \mathrm{TDC}=360\right)$ 

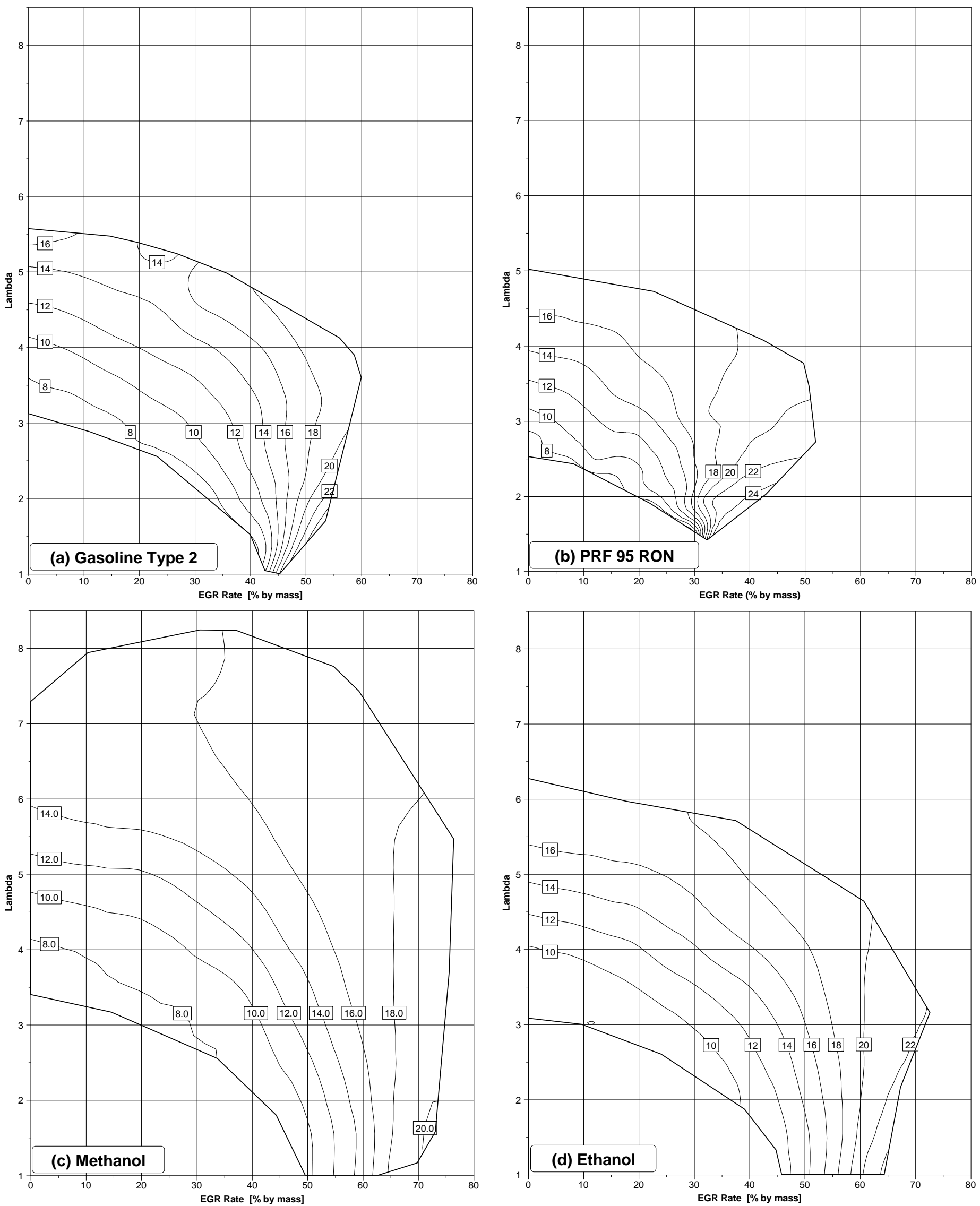

Figure 3 Combustion Duration (10-90\% Burn Crank Angle), $\left({ }^{\circ} \mathrm{CA}\right)$ 

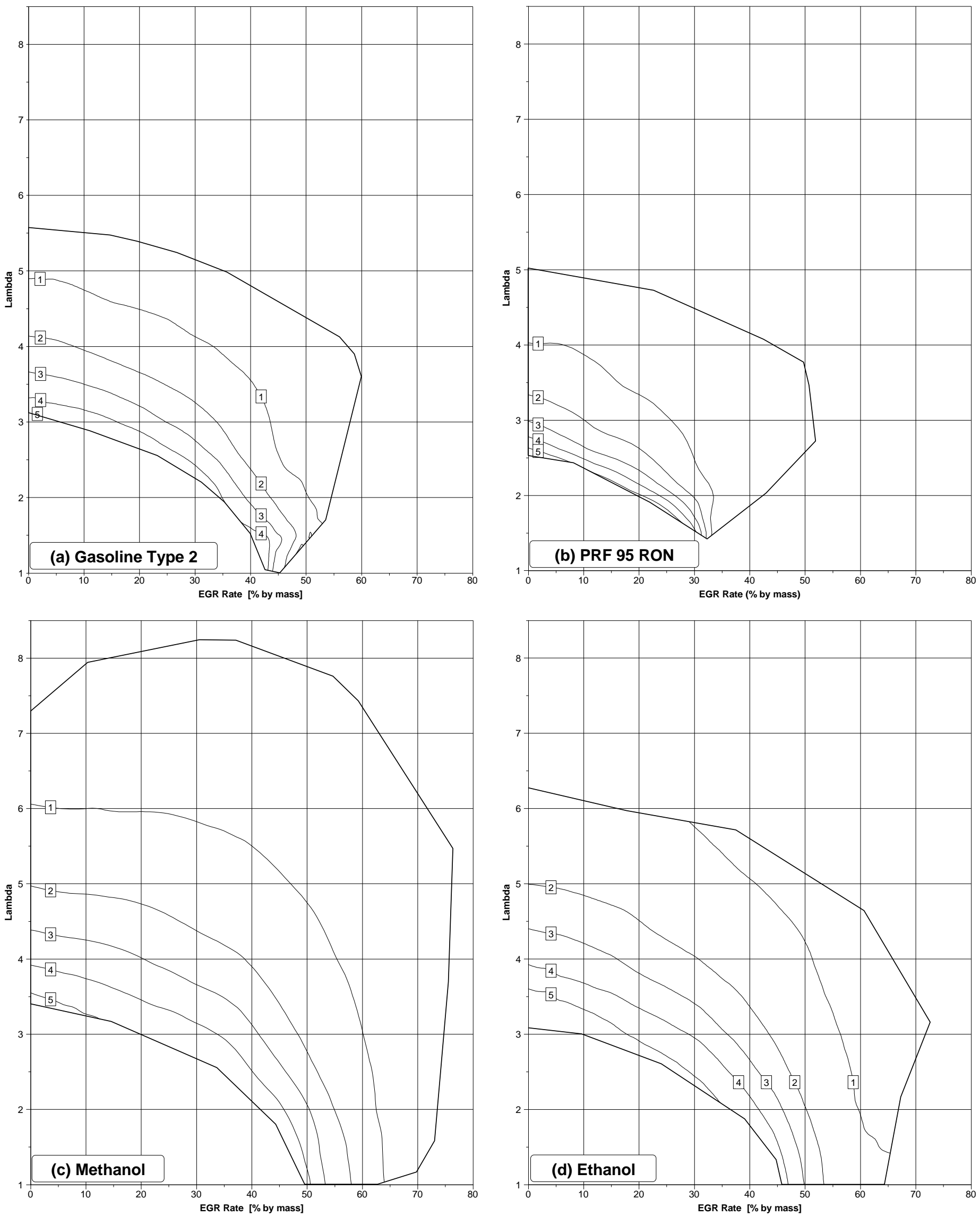

Figure 4 Maximum Rate of Pressure Rise (bar $\left./{ }^{\circ} \mathrm{CA}\right)$ 

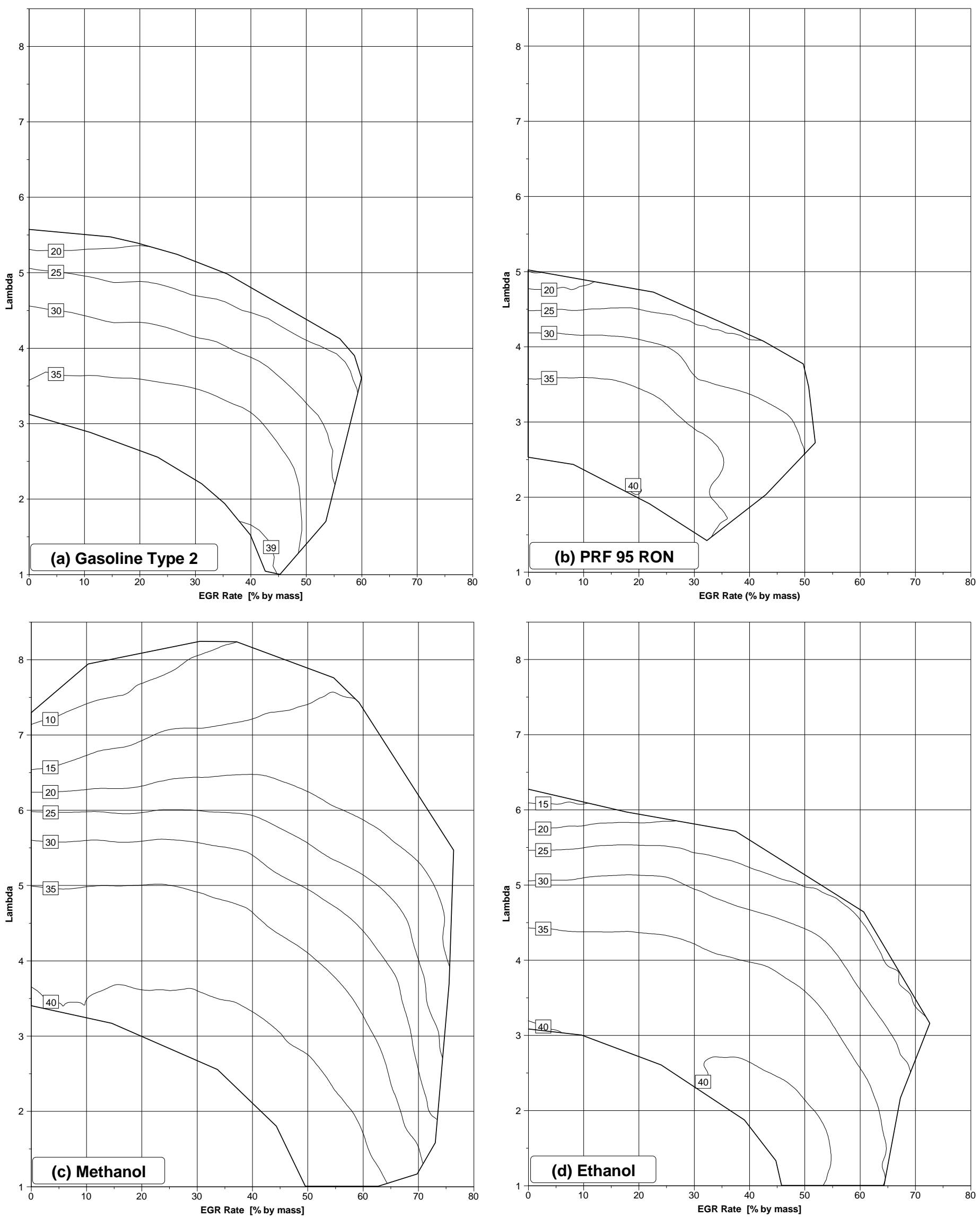

Figure 5

Indicated Thermal Efficiency (\%) 

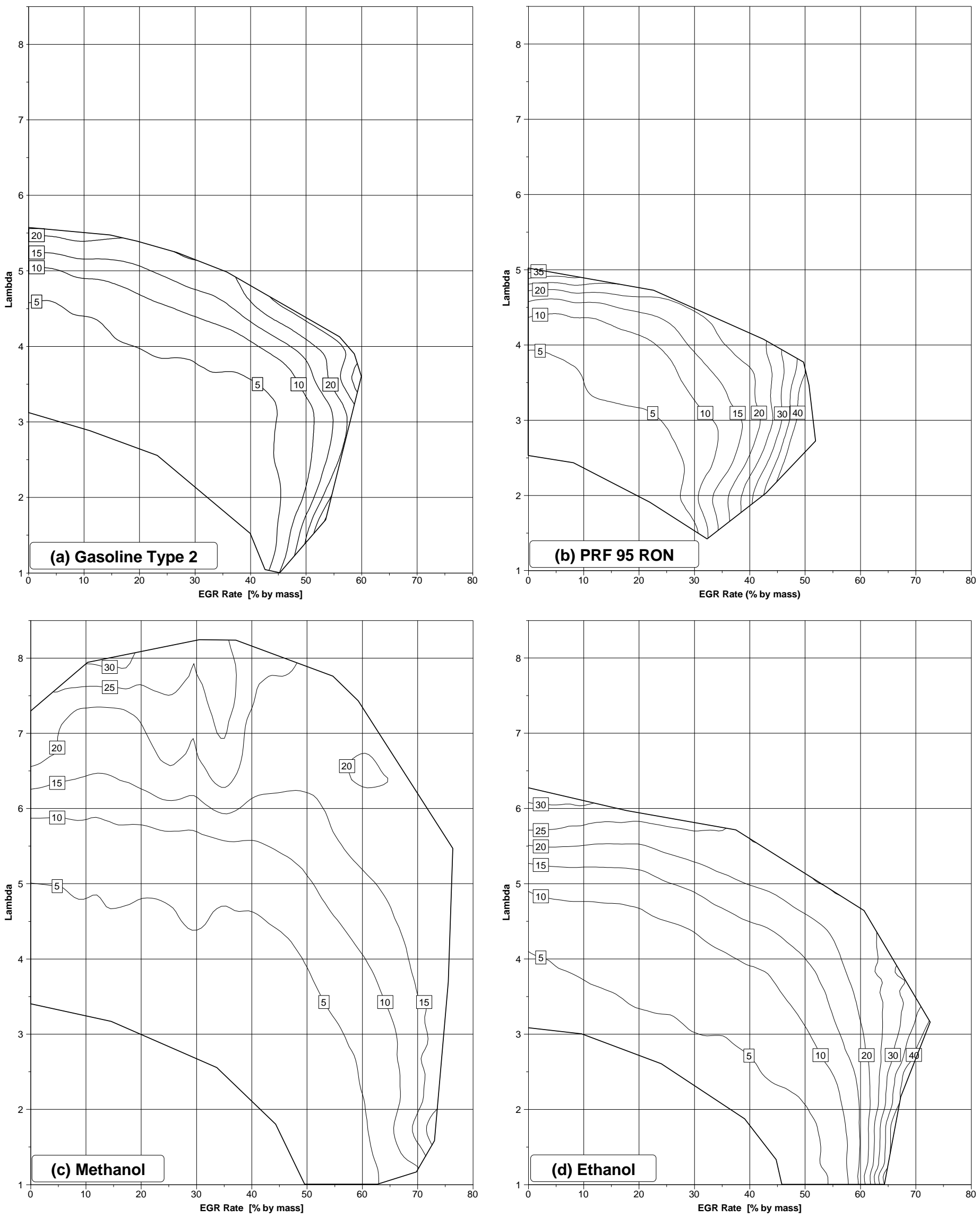

Figure 6 Coefficient of Variation in Indicated Mean Effective Pressure (COVimep), (\%) 

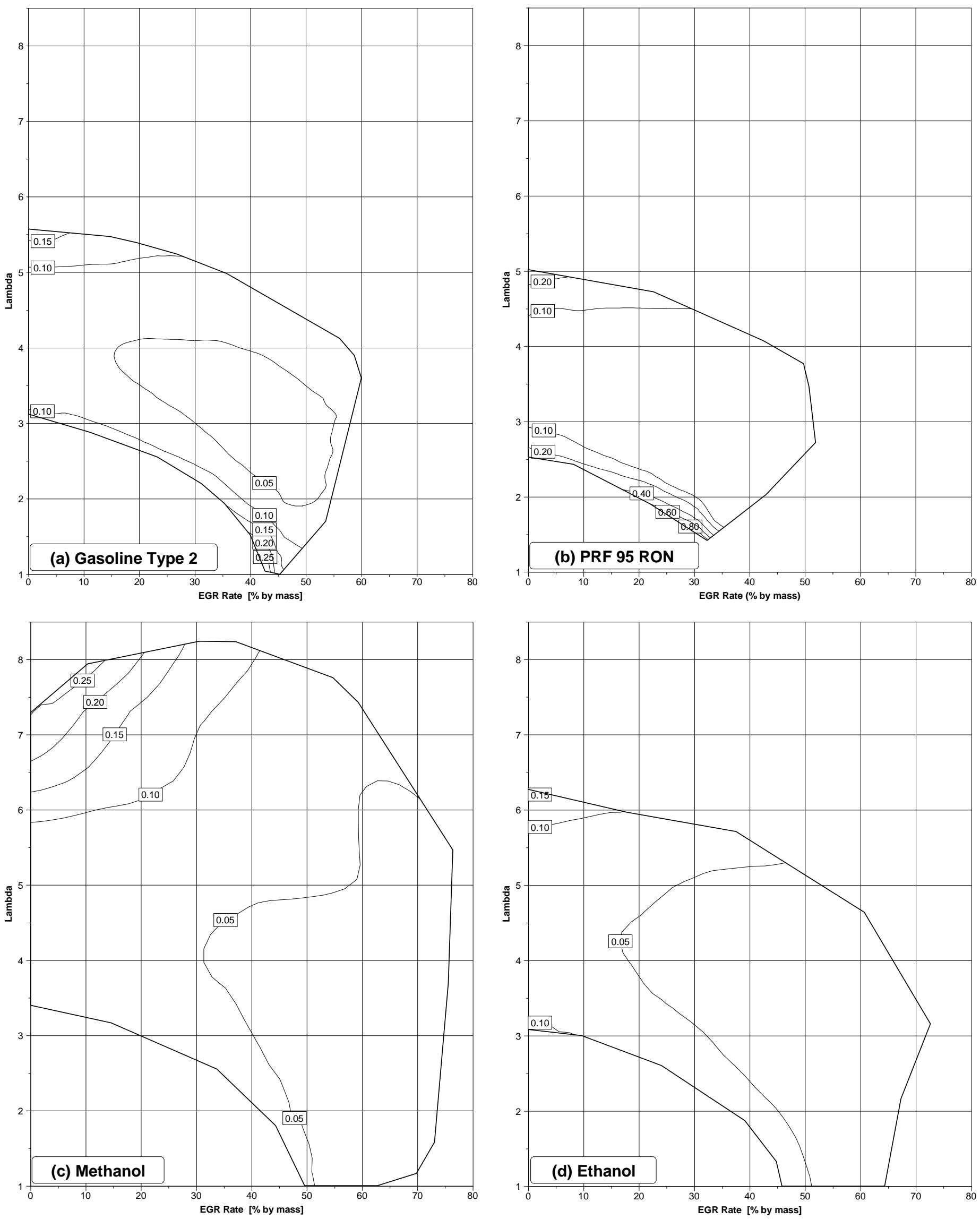

Figure $7 \quad$ Indicated Specific NOx Emissions (g/kW.h) 

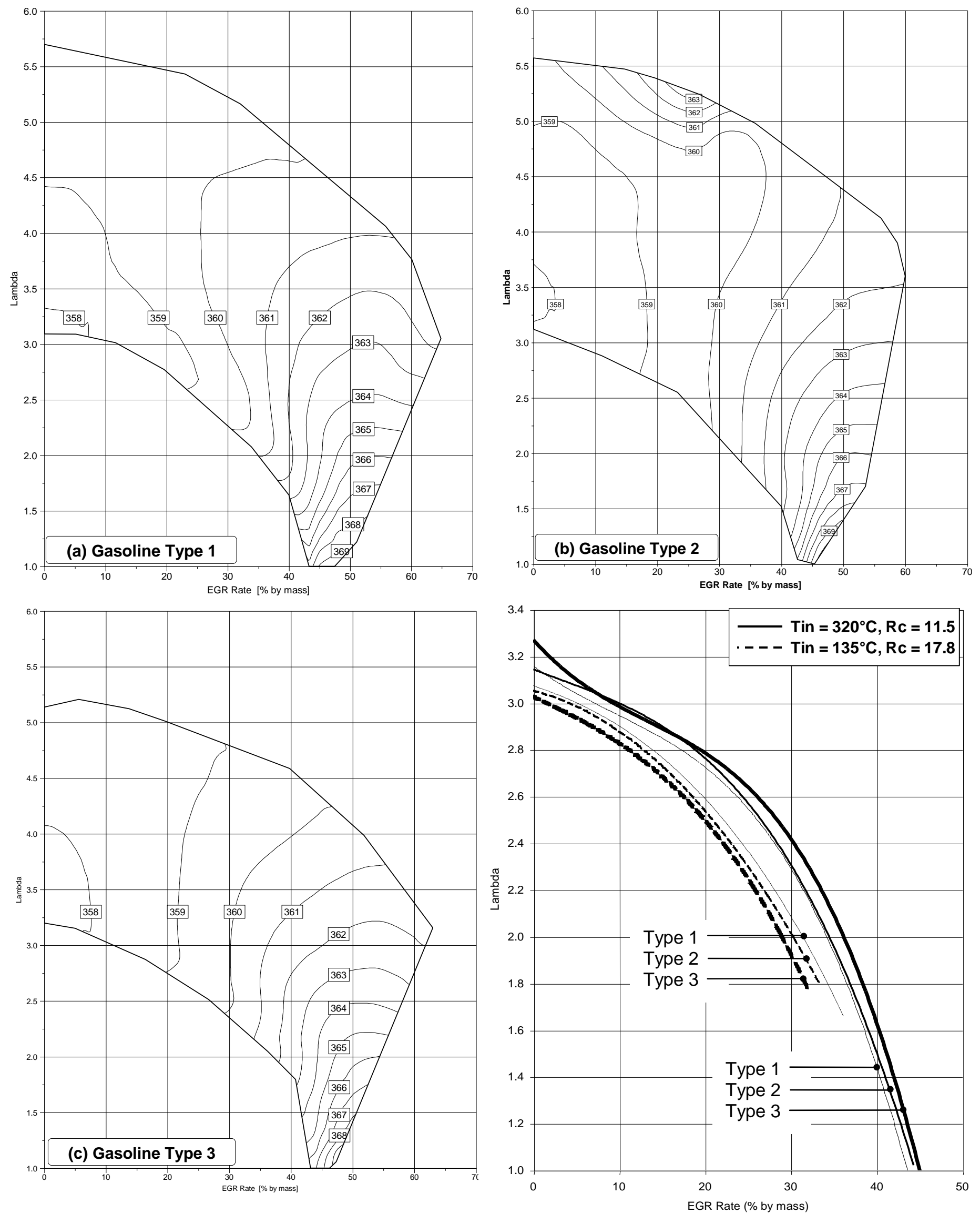

Figure 8

(a), (b), (c)

- Ignition Timing (10\% MFB Crank Angle) for Gasoline Types 1, 2, and 3 Respectively.

(d)

- Knock Boundary for Gasoline Types 1, 2, and 3 under two engine operating conditions. 